\title{
A New Class of Oxo-Bridged High-Valent Hexamanganese Clusters Supported by
} Sterically Hindered Carboxylate Ligands

Sumitra Mukhopadhyay, ${ }^{\dagger}$ Bhavesh A. Gandhi, ${ }^{\dagger}$ Martin L. Kirk, ${ }^{* *}$ and William H. Armstrong, ${ }^{* \dagger}$

Contribution from the Department of Chemistry, Eugene F. Merkert Chemistry Center, Boston College, 2609 Beacon Street, Chestnut Hill, Massachusetts 02467-3860, and the Department of Chemistry, The University of New Mexico, MSC03 2060, 1 University of Mexico, Albuquerque, New Mexico 87131-0001, USA.

Received June XX, 2003

${ }^{\dagger}$ Department of Chemistry, Eugene F. Merkert Chemistry Center, Boston College, 2609 Beacon Street, Chestnut Hill, Massachusetts 02467-3860, USA.

$\$$ Department of Chemistry, The University of New Mexico, MSC03 2060, 1 University of Mexico, Albuquerque, New Mexico 87131-0001, USA.

* Authors to whom correspondence should be addressed. E-mail: armstrow@bc.edu, and mkirk@unm.edu. 


\section{Contents:}

Table S1. ${ }^{1} \mathrm{H}$ NMR resonances of the $\mathrm{Mn}_{6}$ complexes

\section{List of Figures:}

Figure S1. An ORTEP view of $\left[\mathrm{Mn}(\mathrm{dmb})_{2}\left(\mathrm{Ar}^{4-\mathrm{tBuPh}} \mathrm{CO}_{2}\right)\left(\mathrm{OH}_{2}\right)\right](\mathrm{OTf})(2)$ showing $30 \%$ probability ellipsoid and atom labeling scheme. The $\mathrm{H}$ atoms, triflate counter-ions and $\mathrm{CH}_{2} \mathrm{Cl}_{2}$ molecules are omitted for clarity.

Figure S2. ESI mass spectrum of $\left[\mathrm{Mn}_{6} \mathrm{O}_{8}(\mathrm{dmb})_{6}\left(\mathrm{Ar}^{4-\mathrm{BBuPh}} \mathrm{CO}_{2}\right)_{2}\right]\left(\mathrm{ClO}_{4}\right)_{4}(4)$.

Figure S3. ESI mass spectrum of $\left[\mathrm{Mn}_{6} \mathrm{O}_{8}(\mathrm{dmb})_{6}\left(\mathrm{Ar}^{4-\mathrm{HBPh}} \mathrm{CO}_{2}\right)_{2}\right]\left(\mathrm{ClO}_{4}\right)_{4}(4)$ : the $\mathrm{M}^{2+} / 2$ ion peak (bottom) and its simulation (top).

Figure S4. $\mu_{\mathrm{eff}} \mathrm{vs}$. T plot for $\left[\mathrm{Mn}_{6} \mathrm{O}_{8}(\mathrm{dmb})_{6}\left(\mathrm{Ar}^{\mathrm{Tol}} \mathrm{CO}_{2}\right)_{2}\right](\mathrm{OTf})_{4}(\mathbf{3})$. 
Table S1. ${ }^{1} \mathrm{H}$ NMR resonances of the $\mathrm{Mn}_{6}$ complexes

\begin{tabular}{|c|c|c|}
\hline Complex & Chemical Shift (ppm) & Assigned Resonances \\
\hline \multirow[t]{4}{*}{3} & $35.8,31.7,23.8,15.8,9.1,4.4$ & Me-protons of the dmb ligands \\
\hline & $\begin{array}{c}30.3,23.3,14.6,10.7,9.7,7.0,5.8 \\
-3.8,-4.3,-5.1\end{array}$ & $\begin{array}{l}3,3^{\prime}, 5 \text {, and } 5^{\prime} \text { protons on the pyridine } \\
\text { rings of the dmb ligands }\end{array}$ \\
\hline & Between 6.6-5.1 & $\begin{array}{c}\text { Aromatic protons of the } \mathrm{Ar}^{\mathrm{tol}} \mathrm{CO}_{2}^{-} \\
\text {ligands }\end{array}$ \\
\hline & Between 1-3 ppm & $\begin{array}{l}\text { Me-protons of the tolyl rings of the } \\
\qquad \mathrm{Ar}^{\mathrm{tol}} \mathrm{CO}_{2}^{-} \text {ligands }\end{array}$ \\
\hline \multirow[t]{4}{*}{4} & $36.3,32.95,25.6,16.6,7.9,4.7$ & Me-protons of the dmb ligands \\
\hline & $\begin{array}{c}29.8,24.6,15.5,12.7,11.0,9.5,-1.7 \\
-4.2\end{array}$ & $\begin{array}{l}3,3^{\prime}, 5 \text {, and } 5^{\prime} \text { protons on the pyridine } \\
\text { rings of the dmb ligands }\end{array}$ \\
\hline & Between $~ 7.0-5.0$ & $\begin{array}{c}\text { Aromatic protons of the } \mathrm{Ar}^{4 \mathrm{tBuPh}} \mathrm{CO}_{2}^{-} \\
\text {ligands }\end{array}$ \\
\hline & $\sim 3.0$ & ${ }^{\mathrm{t}} \mathrm{Bu}$-protons of the $\mathrm{Ar}^{4 \mathrm{tBuPh}} \mathrm{CO}_{2}^{-}$ligands \\
\hline
\end{tabular}




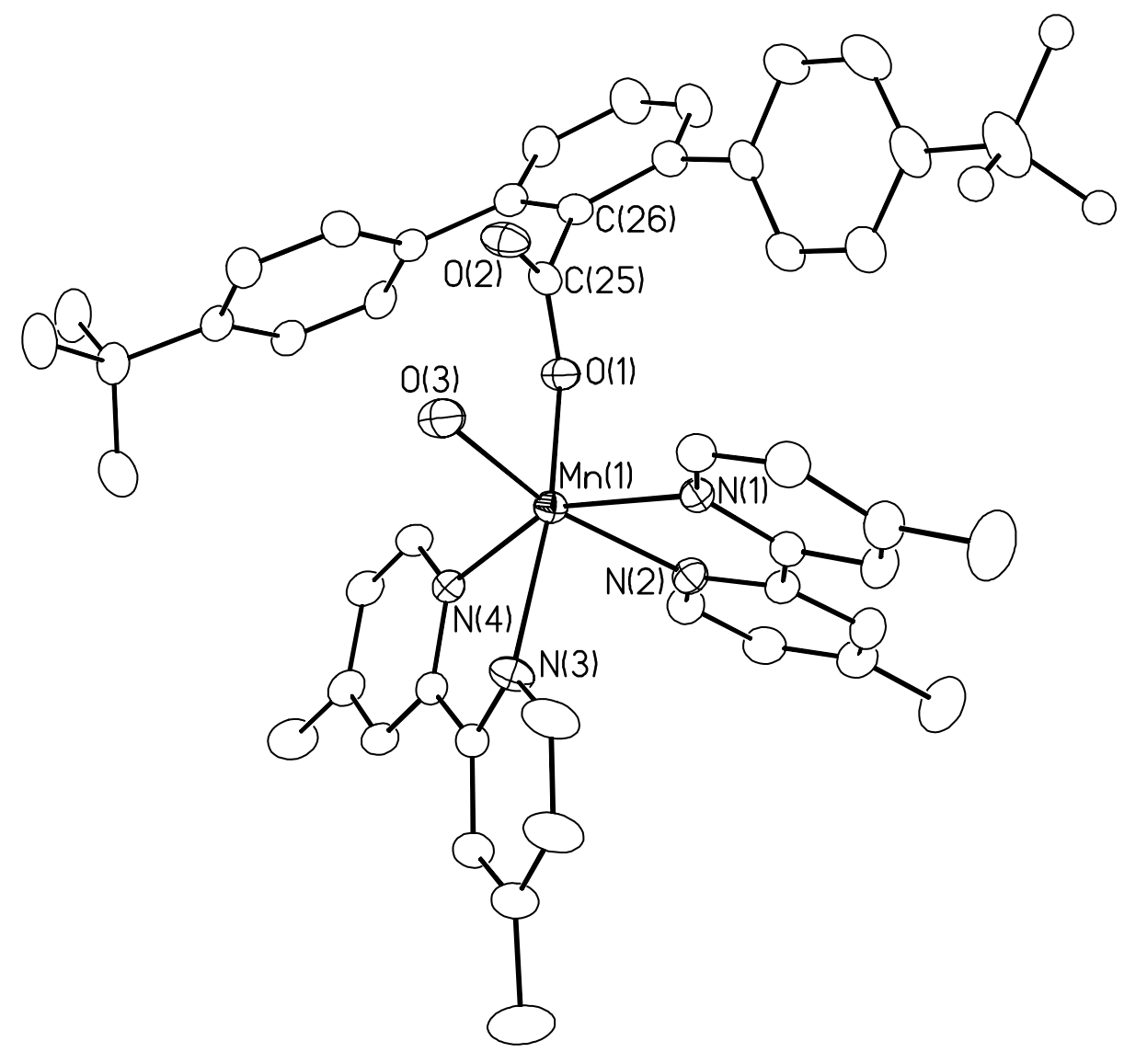

Figure S1. Mukhopadhyay et al. 


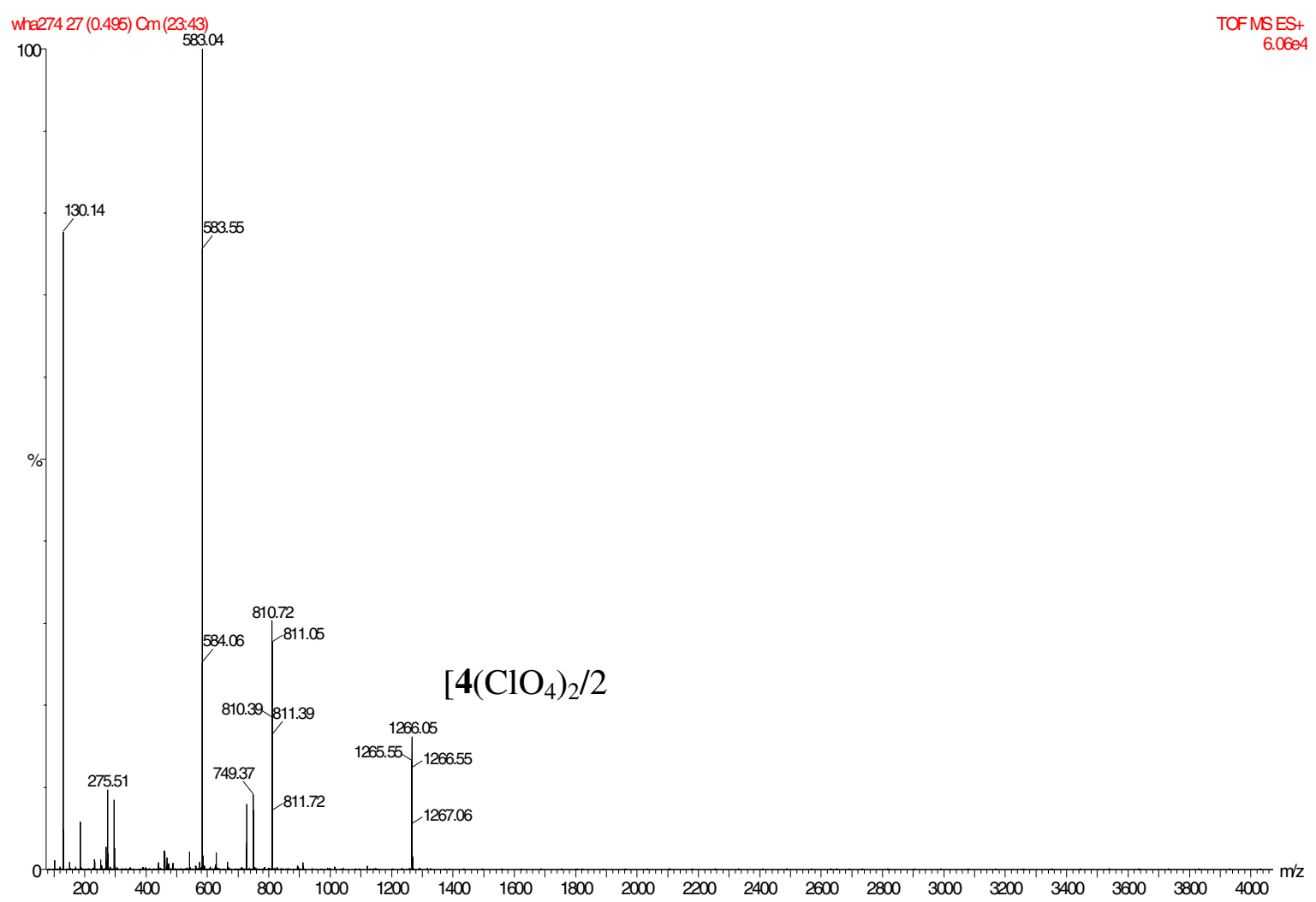

Figure S2. Mukhopadhyay et al. 


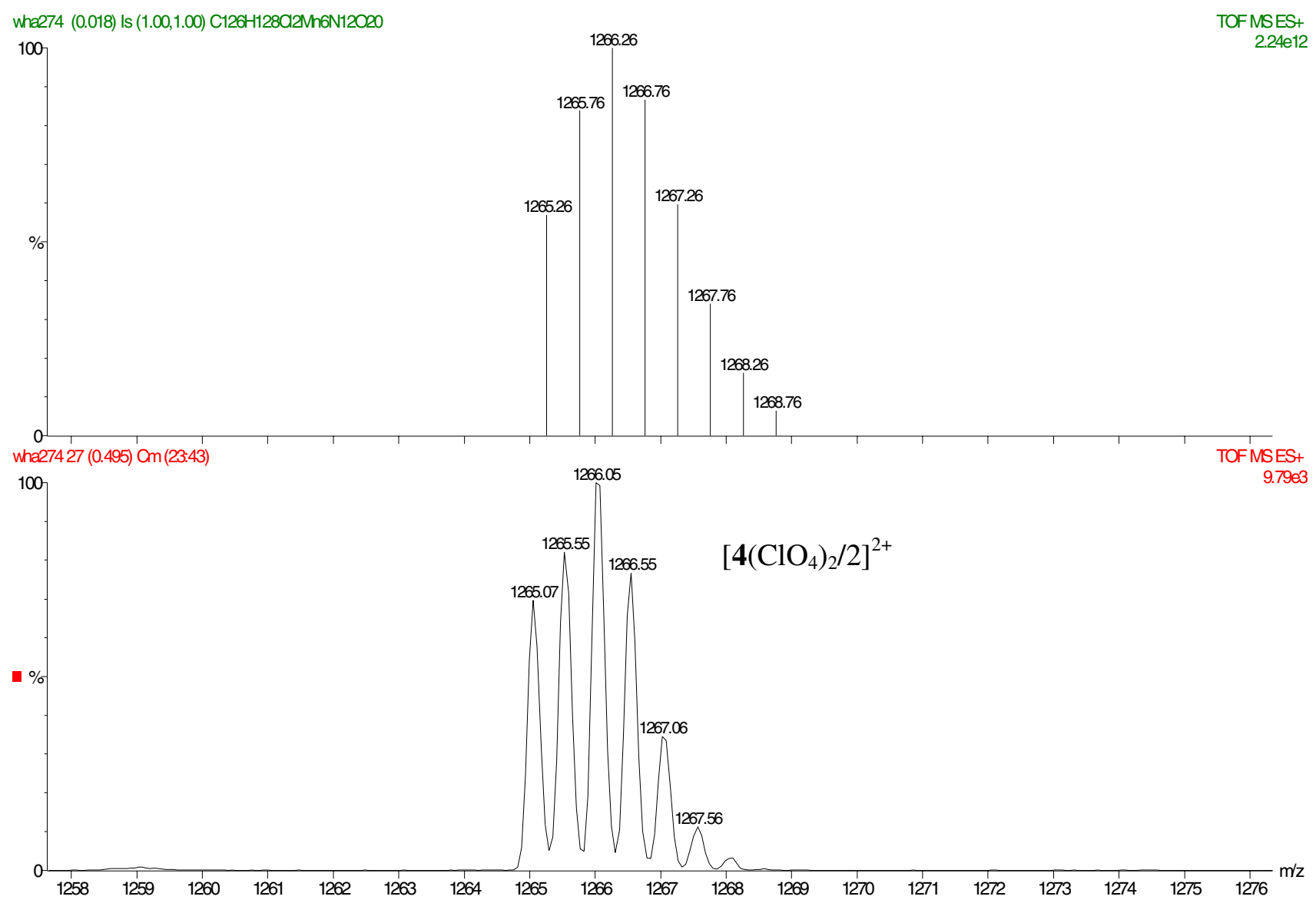

Figure S3. Mukhopadhyay et al. 


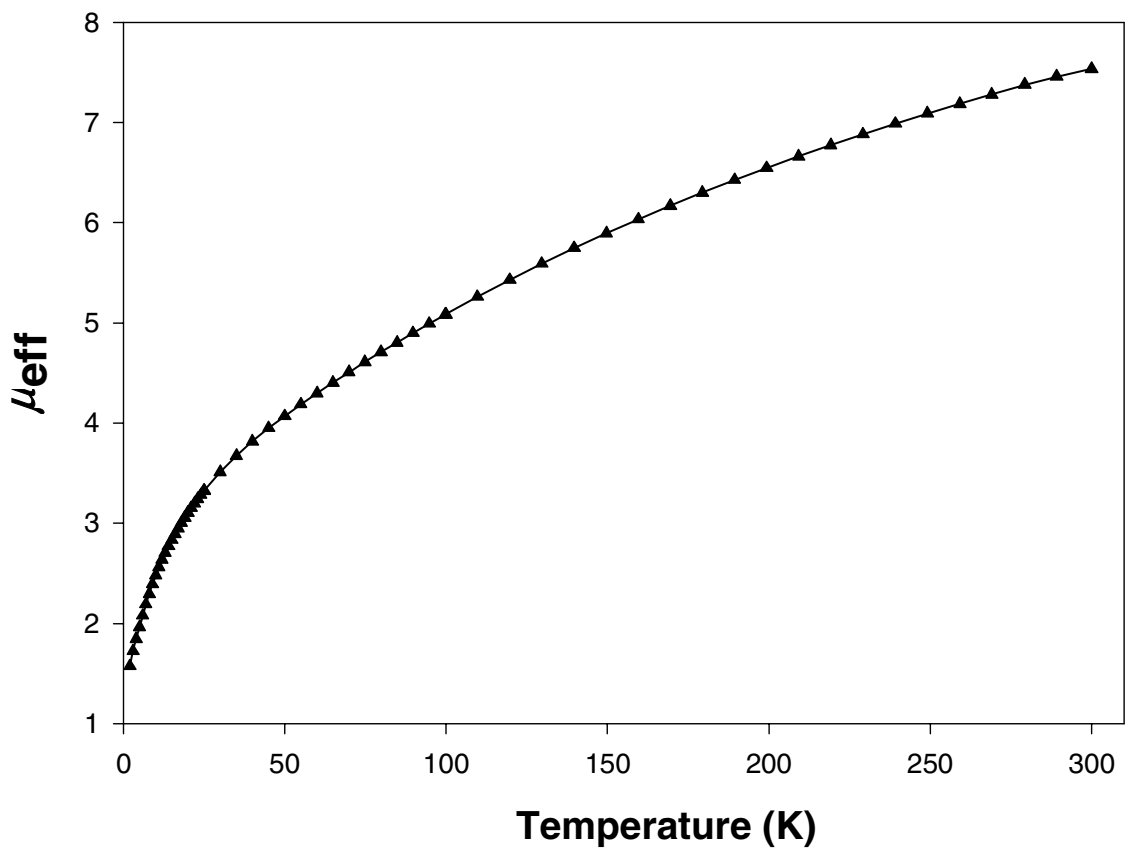

Figure S4. Mukhopadhyay et al. 